\title{
INTRODUCTION TO SPECIAL ISSUE: THE UNIVERSITY OF THE WESTERN CAPE DIGITAL INCLUSION AND WOMEN ENTREPRENEURSHIP SERIES 2021
}

\author{
Michelle Esau' Orcid ID: https://orcid.org/0000-0002-1789-099X
}

This special issue on Digital inclusion and women entrepreneurship features a selection of papers and review articles on themes and issues raised in the University of the Western Cape (UWC) webinar series on the topic held in the 2021 academic year.

To help limit the devastating effects of the COVID-19 pandemic, UWC's academic activities in 2020 and 2021 migrated to online platforms. The university was one of the pioneers of remote learning to ensure that the academic project is saved. As learning and teaching was taking place via online learning platforms, research and collaboration were mediated through webinars. Webinars allowed researchers to continue the practice of gathering and sharing their findings with their peers and the community at large. In the Faculty of Economic and Management Sciences (EMS), we took a conscious decision to focus our webinars on the broad theme of Towards SME recovery from the Covid-19 pandemic. This theme particularly provided the faculty with the opportunity to facilitate engagements, discourse, and debates among women entrepreneurs, researchers of female owned SMMEs, entrepreneurship students, and policymakers. The webinars were well-received and invited much discussion. It was, therefore, imperative for the faculty to ensure that the discussion on female owned SMEs continues. For that reason, the faculty resolved that the faculty's developmental journal - Journal of Entrepreneurial Innovations (JEI) - publish a special issue on the webinar series to ensure that collaboration and engagement on the topic not only continues but was also (re)introduced as an important agenda item in the mainstream literature. This was a bold step by the faculty, as the mainstream literature tends to shy away from research topics involving SMEs and women owned businesses. Despite the evidence supporting that SMEs are responsible for employment creation and poverty alleviation (United Nations, 2020), SMEs are almost always considered to be "too small to make any impact." At EMS, we are committed to improving the welfare of SMEs both in research and practice. The JEI, in general, and this special issue, in particular, as well as other activities including the Small Business Clinic, illustrates that the EMS Faculty is committed to stimulating the craft of entrepreneurship. This special issue reflects on the application of digital and computerised technologies and how these could be utilised to leverage entrepreneurship.

The first paper by Ingrid Lestrade, a female entrepreneur and CEO of Vickispan provides a practitioner perspective on lessons learnt from working with rural farm women in Swartland Municipality. The paper highlights some the power of mobile apps in assisting rural farmers navigate recurring problems in business and how technology helps to overcome these. Naturally, this will help farmers to more effectively manage their farms as businesses.

The second paper by Lisle Svenson, a lecturer in the EMS Faculty provides a very good balance on both the challenges and lessons learnt from the pandemic. The paper speaks about the need for balancing the competing needs of role players in the economy. In particular, the role of policymakers in supporting entrepreneurs is highlighted.

${ }^{1}$ Faculty of Economic and Management Sciences,

University of the Western Cape 
The third paper is a passionate piece written by Dr. Marcia Lebambo who also happens to be a lecturer and an entrepreneur. The paper reports on the author's personal experience of starting (against all odds) and running a business during the COVID-19 pandemic. The paper does bring true the notion that entrepreneurs will only survive and thrive if they are passionate and hardworking (Riani, 2020).

Papers 4 to 6 are short review articles of the presentations in one of the webinars on digital inclusion. These papers provide summaries of the highlights of the issues raised in the webinars.

The last paper: "Voices of Entrepreneurs" does a great job of extrapolating narratives from entrepreneurs and attempts to theorise some of these phenomena. This is such a good paper that highlights and summarises the discussions of the webinar. Above all, it provides a platform for further research in the area of female owned SMEs.

In conclusion, it is important to highlight that COVID-19 does not suggest the end for entrepreneurship, it is an opportunity for SMEs, an opportunity to think more creatively about business ideas and its repositioning in the market. But to realise this opportunity, they need support and guidance.

\section{References}

Riani, A. (2020). 5 Big Challenges to Launching a Startup and How to Overcome Them. Accessed online at: https://www.forbes.com/sites/abdoriani/2020/01/30/5-big-challenges-to-launching-a-startup-and-how-toovercomethem/?sh=a34f1cd33645. [Accessed: 10. January 2021]

United Nations. (2020). Micro, Small and Medium-sized Enterprises (MSMEs) and their role in achieving the Sustainable Development Goals (SDGs).

https://sdgs.un.org/publications/micro-small-and-medium-sizedenterprises-msmes-and-their-role-achievingsustainable. (Accessed 8 August, 2021). 